Jules Verne M. Villanueva, MD

Ronaldo G. Soriano, MD

Department of Otorhinolaryngology

Head and Neck Surgery

Dr. Paulino J. Garcia Memorial Research

and Medical Center

\title{
Advanced Laryngotracheal Stenosis Patients in a Tertiary Provincial Government Hospital: A Prospective Case Series
}

\begin{abstract}
Objective: To describe the clinical profiles, interventions and surgical outcomes of patients with advanced (grade III and IV) laryngotracheal stenosis prospectively seen over a 2-year period.

Methods:

$\begin{array}{ll}\text { Design: } & \text { Prospective Case Series } \\ \text { Setting: } & \text { Tertiary Provincial Government Hospital } \\ \text { Participants: } & \text { Five (5) patients with advanced laryngotracheal stenosis confirmed } \\ & \text { by laryngoscopy and/or tracheoscopy. }\end{array}$
\end{abstract}

Results: Five (5) patients ( 4 males, 1 female), aged 23 to 31 years (mean 27 years old) diagnosed with advanced laryngotracheal stenosis between June 2016 to June 2018 were included in this series. Four resulted from prolonged intubation (14 - 60 days) while one had a prolonged tracheotomy (13 years). Presentations of stenosis included dyspnea on extubation attempt $(n=3)$, failure to extubate $(n=1)$ and failure to decannulate tracheotomy $(n=1)$. Stenosis length was 3 $\mathrm{cm}$ in two and $1.5 \mathrm{~cm}$ in three. Of the five (5) patients, three had grade IV stenosis while two had grade III stenosis based on the Cotton-Myer Classification System. Two of those with grade IV stenosis and both patients with grade III stenosis had undergone prolonged intubation. The stenosis involved the subglottis in three and combined subglottic and tracheal stenosis in two. Prolonged intubation was present in all three with subglottic stenosis and in one of the two with combined subglottic and tracheal stenosis. Two patients underwent open surgical approaches while three underwent endoscopic dilatation procedures. Four patients were successfully decannulated while one is still on tracheostomy. None of them had post-operative complications.

Conclusion: Advanced laryngotracheal stenosis is a challenging entity that results from heterogenous causes. Categorizing stenosis and measuring stenosis length may help in treatment planning and predicting surgical outcome.

Keywords: laryngotracheal stenosis; laryngotracheal reconstruction; tracheal resection anastomosis; subglottic stenosis; tracheal stenosis

Laryngotracheal stenosis (LTS) is a life-threatening, fixed, extrathoracic restriction in pulmonary ventilation' involving a partial or complete cicatricial narrowing of the endolarynx, subglottis or trachea. ${ }^{2}$ Various etiologies include intubation, trauma, infection and local tumors. ${ }^{3}$ A refractory disease with high morbidity, injury is initiated by ischemic necrosis of 
ORIGINAL ARTICLES

the mucosa leading to ulceration of cartilage, inflammation with granulation and fibrous contraction. ${ }^{4}$ It poses a great management challenge to otolaryngologists due to the complexity of the region, including delicate structures such as the vocal cords and recurrent laryngeal nerves that coordinate the functions of respiration, deglutition and phonation. ${ }^{5}$

Laryngotracheal stenosis can be graded based on the percentage of luminal narrowing according to the Cotton-Myer Classification ranging from grade I $(0-50 \%)$ to grade IV (complete obstruction). ${ }^{3}$ There is no standard approach to the management of advanced LTS that includes various modalities from endoscopic dilatations of the stenotic area to open surgical resection of the diseased segment with end-to-end anastomosis. ${ }^{1}$ Moreover, because LTS is not a homogenous clinical entity, understanding the mechanism of injury and comorbidities is critical to treatment. Although a previous local study described the clinical profile of patients with LTS, it focused on "causal factors, presentation, endotracheal tube (ET) intubation (history, indication, ET tube size, duration, frequency of re-intubation, interval from latest extubation until stenosis diagnosis) and grading and location of stenosis."4 Furthermore, the study was conducted in the highly-urbanized national capital region, a context quite different from ours. To the best of our knowledge, no previous study has been published describing treatment outcomes for LTS in a setting similar to our locality.

Thus, our study aims to describe the clinical profiles, interventions and surgical outcomes of patients prospectively diagnosed with advanced (grade III and IV) laryngotracheal stenosis over a 2-year period in our tertiary provincial hospital.

\section{METHODS}

With institutional review board approval, this prospective case series sought to enroll patients of all age groups diagnosed with advanced (grade III and IV) LTS at the Dr. Paulino J. Garcia Memorial Research and Medical Center in Cabanatuan City, Nueva Ecija between June 2016 and June 2018.

After obtaining written informed consent, a thorough history was obtained and physical examination with clinical evaluation including laryngoscopy for airway assessment and vocal cord mobility was carried out by the author for all the patients in the study. A noncontrast and contrast-enhanced computed tomographic (CT) scan of the neck was performed. The diagnosis of LTS was further confirmed by endoscopic evaluation of the larynx and trachea under general anesthesia to assess the site and grade of stenosis based on the CottonMyer Grading Classification (see below). The age, sex, probable cause of stenosis, presentation of stenosis, history of endotracheal tube (ET) intubation (including the ET tube size and total duration of intubation) and stenosis morphology (site and grade of stenosis) were recorded by pen and paper using a data collection sheet. For this study, grade I or grade II stenosis was classified as early LTS whereas grade III or grade IV stenosis was classified as advanced stenosis. Patients with laryngeal malignancy and early laryngotracheal stenosis were excluded.

Treatment options for LTS included endoscopic dilatation of stenosis and open surgical resection of the stenotic segment with end-to-end anastomosis. All candidates for surgical management were tracheotomised prior to the procedure and initial laryngotracheoscopy was carried out under general anesthesia. Patients with stenosis 2 $\mathrm{cm}$ or more below the stenotic segment were offered open surgical reconstruction while those with less than $2 \mathrm{~cm}$ stenosis were offered endoscopic dilatation. Following surgical interventions, initial review was scheduled one-week post-surgery to assess healing and to evaluate for any post-operative complications. Following this, patients were generally reviewed once in 2-4 weeks in case of endoscopic intervention and after 8-12 weeks in case of open surgery. Successful surgical intervention was defined as decannulation of tracheostomy and restoration of the laryngo-tracheal lumen with nasal breathing. Another follow-up was scheduled 6 months post-decannulation to evaluate for re-stenosis.

Interventions and results were tabulated using the previouslydescribed data collection sheet and simple descriptive statistics were used to analyze the data.

\section{RESULTS}

A total of five patients (four males, one female) were evaluated for laryngotracheal stenosis from June 2016 to June 2018 and all of them were included in this study. All five patients were adults with ages ranging from 23 to 31 years old (mean age of 27 years old. Four had LTS following prolonged intubation ( $14-160$ days) while one had prolonged tracheotomy (13 years). The indications for ET intubation were altered sensorium secondary to strangulation injury, vehicular accident and snake bite envenomation and caustic substance ingestion (insecticide). The patient with outright tracheotomy had a clothesline injury. Presentations included dyspnea on extubation attempt in three, failure to extubate in one and failure to decannulate tracheotomy in another. All intubated patients had ET tubes compatible with their ideal size for age. The length of stenosis was 3 $\mathrm{cm}$ in two patients and $1.5 \mathrm{~cm}$ in three. Of the five patients, three had grade IV stenosis while the two had grade III stenosis. Two each of the intubated patients had grade III and IV stenosis respectively. Based on the site of stenosis, three were subglottic and two were combined subglottic and tracheal. All three subglottic stenoses involved intubated patients while one of the two combined subglottic and tracheal stenosis patients was intubated. Table 1 shows the probable causes and presentations of stenosis, total duration of intubation (days) and length, grade and location of stenosis in these 5 patients.

Two patients underwent open surgical approaches while three underwent endoscopic dilatation procedures. The first two cases with 
ORIGINAL ARTICLES

Philippine Journal Of Otolaryngology-Head And Neck Surgery

VOL. 34 No. 1 JANUARY - JUNE 2019

PJOHLS

Table 1. Clinical Profile of Laryngotracheal Stenosis Patients from June 2016 to June 2018.

\begin{tabular}{|c|c|c|c|c|c|c|c|}
\hline Age & Sex & $\begin{array}{c}\text { Probable Cause } \\
\text { of Stenosis }\end{array}$ & $\begin{array}{l}\text { Presentation of } \\
\text { Stenosis }\end{array}$ & $\begin{array}{l}\text { Total Duration of } \\
\text { Intubation (days) }\end{array}$ & $\begin{array}{l}\text { Length of } \\
\text { Stenosis (cm) }\end{array}$ & $\begin{array}{c}\text { Stenosis } \\
\text { Grade }\end{array}$ & $\begin{array}{l}\text { Stenosis } \\
\text { Location }\end{array}$ \\
\hline 29 & M & Clothesline Injury & $\begin{array}{l}\text { Failure to decannulate } \\
\text { tracheotomy }\end{array}$ & - & 3 & IV & $\begin{array}{l}\text { Subglottis + } \\
\text { Trachea }\end{array}$ \\
\hline 23 & M & $\begin{array}{l}\text { Intubation due to } \\
\text { altered sensorium } \\
\text { secondary to } \\
\text { strangulation injury }\end{array}$ & $\begin{array}{c}\text { Dyspnea on } \\
\text { extubation attempt }\end{array}$ & $\begin{array}{c}21 \\
\text { Converted to } \\
\text { tracheostomy }\end{array}$ & 3 & IV & $\begin{array}{l}\text { Subglottis + } \\
\text { Trachea }\end{array}$ \\
\hline 31 & $M$ & $\begin{array}{l}\text { Intubation due } \\
\text { to Snake Bite } \\
\text { Envenomation }\end{array}$ & Failure to extubate & $\begin{array}{c}60 \\
\text { Converted to } \\
\text { tracheostomy }\end{array}$ & 1.5 & IV & Subglottis \\
\hline 25 & $\mathrm{~F}$ & $\begin{array}{c}\text { Intubation due to } \\
\text { altered sensorium } \\
\text { secondary to vehicular } \\
\text { accident }\end{array}$ & $\begin{array}{c}\text { Dyspnea on } \\
\text { extubation attempt }\end{array}$ & $\begin{array}{c}14 \\
\text { Converted to } \\
\text { tracheostomy }\end{array}$ & 1.5 & III & Subglottis \\
\hline 28 & M & $\begin{array}{l}\text { Intubation due to } \\
\text { caustic substance } \\
\text { ingestion (insecticide) }\end{array}$ & $\begin{array}{c}\text { Dyspnea on } \\
\text { extubation attempt }\end{array}$ & $\begin{array}{c}19 \\
\text { Converted to } \\
\text { tracheostomy }\end{array}$ & 1.5 & III & Subglottis \\
\hline
\end{tabular}

a stenosis length of $3 \mathrm{~cm}$, grade IV stenosis and a combined subglottic and tracheal stenosis underwent open (external) surgical approaches. All three cases that underwent endoscopic approaches had a stenosis length of $1.5 \mathrm{~cm}$ with two having grade III stenosis and one having grade IV stenosis.

Four patients were successfully decannulated while one is still on tracheostomy. None of the patients had post-operative complications such as bleeding, surgical site infection or difficulty of breathing. However, the patient still on tracheostomy underwent a second endoscopic dilatation procedure and is yet to be evaluated for decannulation.

\section{DISCUSSION}

Laryngotracheal stenosis (LTS) remains a challenging condition for otolaryngologist - head and surgeons. The airway is compromised by submucosal fibrosis and scar contraction that result from healing by secondary intention involving the larynx, trachea or both. ${ }^{4}$ It is seen more commonly in the age group of 26-34 years. ${ }^{1}$ Consistent with the literature, the mean age in our study was 27 years with male predilection.

In our study, stenosis was seen in three patients following ET intubation. Laryngotracheal stenosis is one of the most frequent sequelae of prolonged nasal/orotracheal intubation and tracheotomy. Approximately $10 \%$ of intubated patients develop laryngotracheal stenosis $^{3}$ with a $0-2 \%$ incidence of subglottic stenosis ${ }^{6}$ and $6-21 \%$ incidence of tracheal stenosis. ${ }^{7}$ The incidence of tracheal stenosis following tracheotomy ranges from $0.6-21 \% .^{7}$ The endotracheal tube causes erosion and mucosal necrosis just within hours. ${ }^{4}$ The aptness of
ET tube size was not a factor in causing stenosis since the ideal ET tube size for age was used in the study. However, pressure from the tube can cause full thickness injury that can expose cartilage predisposing to perichondritis with subsequent scarring and necrosis. ${ }^{4}$

The duration of ET intubation in our study ranged from 14 to 60 days before converting to tracheostomy. In adults, orotracheal intubation for more than 96 hours has been associated with permanent damage. ${ }^{4}$ In fact, stenosis was seen in $2 \%$ of patients who were intubated between 3-5 days while it increased to $5 \%$ when intubation reached 6-10 days. ${ }^{7}$ There is no safe time limit before considering tracheostomy in an intubated patient. However, longer intubation periods correlated with broader and deeper ulcers, injury in the subglottis and posterior glottis. ${ }^{11}$

In our study, the length of stenosis assessed intraoperatively significantly correlated with the data obtained from neck CT and direct laryngoscopy with tracheoscopy. The sensitivity and specificity of both CT and tracheobronchoscopy in the detection of subglottic stenosis has been reported to be $100 \%{ }^{2}$ It has also been reported that the detection rate for tracheal stenotic lesions was $94 \%$ by CT and $88 \%$ by rigid bronchoscopy. ${ }^{2}$ A preoperative assessment of the length of stenosis was accurate in $87 \%$ of the stenotic segments detected by CT and in $73 \%$ of the segments detected by bronchoscopy. ${ }^{8}$

The severity (degree of narrowing) is graded by the Cotton-Myer Classification system, based on the percentage of obstruction -- Grade I (from 0 to 50\%) Grade II (51-70\%), Grade III (71-99\%) and Grade IV (no detectable lumen). ${ }^{9}$ Two of our patients had grade IV stenosis while three had grade III stenosis. Previous studies have shown that lowgrade stenosis and a stenosis inferior to $50 \%$ of total tracheal extension 
ORIGINAL ARTICLES

seem to have better prognosis. ${ }^{7}$ We could neither observe this nor infer anything because our study excluded Grade I and II stenoses.

Surgical repair of LTS involves two basic modalities: 1) external (laryngotracheoplasty, laryngotracheal resection with end-to-end anastomosis); and 2) endoscopic (laryngeal microsurgery, laser-assisted excision, traditional dilatation and endoscopic stent insertion).,7 In our series, the external and endoscopic approaches used were laryngotracheal resection with anastamosis and traditional dilatation without stent, respectively. Stenosis length is one of the factors that determines treatment option. In patients who required multiple dilatation procedures and with stenosis length of at least $2 \mathrm{~cm}$, a consideration for open surgical approach was offered. Two of our patients with a stenosis length of $3 \mathrm{~cm}$ underwent external approaches while three with stenosis lengths of $1.5 \mathrm{~cm}$ underwent endoscopic approaches.

The ultimate outcome in open treatment of LTS is removal of the stenotic segment with laryngotracheal reconstruction establishing a normal nasal breathing pattern without periods of pulmonary distress and prevention of re-stenosis. ${ }^{5}$ If the tracheostomy is not successfully removed within 3 interventions (whether endoscopic or open approach), the odds of decannulating the patient decrease significantly, and additional surgeries may not be beneficial especially in older patients and in those with higher grade stenosis.? In our series, only one of our five patients underwent repeat endoscopic dilatation and has not yet been decannulated as of this writing.

Limitations of this study are many. The small sample size and lack of comparators, as well as our exclusion of patients with grade I and II stenosis seriously impair our ability to obtain a comprehensive picture of LTS in our locality. In terms of procedure, our study failed to perform laryngotracheoscopy prior to converting to tracheostomy and did not record the number of re-intubations. It would be helpful if future studies would address these shortcomings.

In conclusion, our findings confirm that advanced laryngotracheal stenosis is a challenging entity that results from heterogenous causes. Categorizing stenosis and measuring stenosis length may help in treatment planning and predicting surgical outcome.

\section{REFERENCES}

1. Gelbard A, Francis DO, Sandulache VC, Simmons JC, Donovan DT, Ongkasuwan J. Causes and consequences of adult laryngotracheal stenosis. Laryngoscope. 2015 May; 125(5): 1137-43. DOI: 10.1002/lary.24956; PMID: 25290987 PMCID: PMC4562418.

2. Ramdev S, Ghosh P, Mukhopadhyaya S. Radiological Evaluation of Chronic Laryngotracheal Stenosis. Indian J Otolaryngol Head Neck Surg.2005 Apr; 57(2): 108-109. DOI: 10.1007/ BF02907661; PMID: 23120143 PMCID: PMC3450972.

3. Janssen LM. Laryngotracheal stenosis and reconstruction. [Internet]. Erasmus University Rotterdam; 2010. [cited 2018 Jul 16]. Available from: http://hdl.handle.net/1765/19828.

4. Arriola AC, Chua A. Clinical profile of patients with laryngotracheal stenosis in a tertiary government hospital. Philipp J Otolaryngol Head Neck Surg. 2016; 31 (1): 26-30. DOI: 10.32412/ pjohns.v31i1.309.

5. Marulli G, Rizzardi G, Bartolotti L, Loy M, Breda C, Hamad AM, et al. Single-staged laryngotracheal resection and reconstruction for benign strictures in adults. Interact Cardiovasc Thorac Surg. 2008 Apr; 7(2): 227-230. DOI: 10.1510/icvts.2007.168054; PMID: 18216046.

6. Tantinikorn W, Sinrachtanant C, Assanasen P. How to overcome laryngotracheal stenosis. J Med Assoc Thai. 2004 Jul; 87(7): 800-9. PMID: 15521236.

7. Gallo A, Pagliuca G, Greco A, Martellucci S, Mascelli A, Fusconi M, et al. Larygotracheal stenosis treated with multiple surgeries: experience, results and prognostic factors in 70 patients. Acta Otorhinolaryngol ltal. 2012 Jun; 32(3): 182-8. PMID: 22767984 PMCID: PMC3385058.

8. Morshed K, Trojanowska A, Szymanski M, Trojanowski P, Szymanska A, Smolen A, Drop A. Evaluation of tracheal stenosis: comparison between computed tomography virtual tracheobronchoscopy with multiplanar reformatting, flexible tracheofiberoscopy and intraoperative findings. Eur Arch Otorhinolaryngol. 2011 Apr; 268(4): 591-7. DOI: 10.1007/s00405 010-1380-2; PMID: 20848120 PMCID: PMC3052474.

9. Myer CM 3rd, O'Connor DM, Cotton RT. Proposed grading system for subglottic stenosis based on endotracheal tube sizes. Ann Otol Rhinol Laryngol. 1994 Apr; 103 (4 Pt 1):319-23. DOI: 10.1177/000348949410300410; PMID: 8154776.

10. Zalzal GH, Cotton RT. Glottic and Subglottic Stenosis. In Flint PW, Haughey BH, Lund VJ, Niparko JK, Robbins KT, Thomas JR, et al (editors). Cummings Otolaryngology Head and Neck Surgery. $6^{\text {th }}$ ed. Vol. III. 2015. Philadel phia, PA: Elsevier Saunders. pp. 3158-3182

11. Divatia JV, Bhowmick K. Complications of endotracheal intubation and other airway management procedures. Indian J Anesth. 2005; 49 (4): 308-318. 